https://doi.org/10.24201/aap.2021.321

INFORME

\title{
Camboya en 2020: la política de la covid, los casinos y el desastre ecológico
}

\section{Cambodia in 2020: The Politics of Covid, Casinos, and Ecological Disaster}

\author{
JOHN A. MARSTON \\ https://orcid.org/0000-0002-2542-4710 \\ El Colegio de Mexico, A.C., México
}

Recepción: 15 de octubre de 2020

Aceptación: 2 de noviembre de 2020

Resumen: El presente artículo analiza sucesos que ocurrieron en Camboya desde fines de 2019 hasta octubre de 2020, muchos de los cuales tienen que ver, en diferentes sentidos, con la relación con China, que se está intensificando. Como consecuencia de la supresión de su principal partido opositor, los europeos degradaron el estatus comercial de Camboya, a lo que China respondió con su propio tratado comercial bilateral. El desarrollo de la pandemia de coronavirus fue dramático, como en el resto del mundo, y aunque al final se reportaron muy pocos casos, ejerció un gran impacto sobre la economía, la vida social y, quizá, los derechos humanos en Camboya. Podría decirse que el suceso más importante del año fue la reducción significativa del caudal del río Mekong, que algunos atribuyeron a presas y embalses río arriba, muchos de ellos en China.

Palabras clave: Camboya; covid-19 en el Sureste Asiático; relaciones entre el Sureste Asiático y China; río Mekong; Sihanoukville. 
Abstract: The article analyzes events in Cambodia from late 2019 until October 2020, many of which relate in different ways to its intensifying relationship with China. As a repercussion of the suppression of its major opposition party, the European downgraded Cambodia's trade status, and China responded with its own bilateral trade agreement. The coronavirus pandemic played out dramatically, as in the rest of the world, and although very few cases were eventually reported, it had great impact on Cambodian economy, social life, and, perhaps, human rights. Arguably, the most important development of the year was the dramatic decrease in water flow of the Mekong River, which some attributed to upstream dams and reservoirs, many in China.

Keywords: Cambodia; Covid-19 in Southeast Asia; Southeast Asia-China relations; Mekong River; Sihanoukville.

Los pormenores de la relación creciente entre Camboya y China, que con frecuencia están muy vinculados en su relación cambiante con Europa y Estados Unidos, fueron especialmente sobresalientes durante el año, pues influyeron en la experiencia del país con la covid-19, pero también en aspectos importantes de política interna, economía, agricultura y medio ambiente. Si bien los vínculos económicos y diplomáticos del país con China, que cada vez son más fuertes, de ninguna manera son una tendencia nueva, algunos de los costos y las complejidades de la relación se volvieron más evidentes, como dejaron ver las posturas de Camboya a propósito de la presencia china en la ciudad portuaria de Sihanoukville y en la crisis ecológica que se acerca en el río Mekong y el lago Tonle Sap, que es más trascendente.

\section{PolíticA}

La disolución forzada en 2017 del único partido de oposición verdadero, el Partido Nacional para el Rescate de Camboya (PNRC), implicó que la victoria del primer ministro Hun Sen y su Partido Popular de Camboya (PPC) en la elección de 2018 básicamente no significara nada. El gobierno de Hun Sen adquirió cada vez más los atavíos de una monarquía. Durante muchos años se ha tenido la percepción de que el hijo de Hun Sen, Hun Maneth, ha estado 
recibiendo preparación para suceder a su padre. Por su parte, Hun Sen lo afirmó en público por primera vez en junio de 2020. Manet, que recibió parte de su educación en Estados Unidos y en Gran Bretaña y ya es comandante de las fuerzas armadas y miembro del comité central del partido, se convirtió en el líder de la organización para jóvenes de dicho comité en 2020. Algunos interpretaron un discurso de septiembre de 2020, en el que condenó abiertamente a las fuerzas del caos que representaba el PNRC, como una declaración de su mandato, posicionándose como sucesor de su padre.

La supresión del PNRC fue muy criticada en el ámbito internacional y las repercusiones continúan sintiéndose en 2020. Sam Rainsy, antiguo copresidente del partido, quien vive exiliado en Francia y a quien sigue identificándose con el PNRC, enfrenta una pena carcelaria por difamación si regresa Camboya. No obstante lo anterior, intentó volver por todo lo alto en noviembre de 2019, cuando llegó hasta Malasia e Indonesia después de que se cancelara su primer vuelo a Tailandia (Kijewski 2019a) (Vietnam y Laos también le habían negado la entrada). Por solicitud del gobierno de Camboya, no se le permitió abordar vuelos al país. Asimismo, otros miembros del PNRC exiliados se incluyeron en listas de no entrada. (Una señal de la seriedad con que se tomó este tema fue el despliegue de Fuerzas Armadas en el aeropuerto de Phnom Penh y en Poipet, el mayor cruce fronterizo con Tailandia. Los oficiales de policía en Phnom Penh llevaban fusiles AK-47.)

El día después de que se prohibiera la entrada al país a Sam Rainy, su contraparte, Kem Sokha, el presidente titular que quedaba del PNRC y que estaba en prisión desde 2017, se trasladó a arresto domiciliario en espera de su juicio en enero, aunque se le impidió salir del país o hacer declaraciones políticas. Otros 70 prisioneros miembros del PNRC fueron puestos en libertad bajo fianza al mismo tiempo y todos serán sometidos a juicio en algún momento. Tras la liberación de Kem Sokha, varios embajadores de países occidentales tuvieron el gesto de visitarlo en su casa. Se le acusa de colusión con potencias extranjeras para derrocar al gobierno, con pocas pruebas como sustento (más bien, las pruebas parecen ser consejos que recibió para su campaña de algunas ONG estadunidenses.) Diversas organizaciones de derechos humanos y relatores especiales de Naciones Unidas para derechos humanos y la independencia del poder judicial criticaron abiertamente su juicio, que inició en enero. Hubo grandes restricciones para la asistencia de público a las audiencias 
y muchos reporteros locales y representantes de diferentes ONG no pudieron asistir. Se cuestionó a Sokha sobre su relación con Estados Unidos y sus motivos para aliarse políticamente con Sam Rainsy. El juicio se suspendió en marzo debido a la propagación del coronavirus y, para mediados de septiembre, aún no se había reprogramado. En mayo, Sokha asistió al funeral de la madre del primer ministro Hun Sen y se le vio sostener una prolongada conversación con el líder. En julio se reportó que había comenzado a viajar por el país, haciendo visitas "no políticas" a granjas y a un sitio de siembra de árboles (lo que quizá sea una manera de afirmar su presencia continua) e insistiendo en la naturaleza no política del viaje cuando hizo donaciones de arroz a las víctimas de las inundaciones en Sihanoukville. A inicios de septiembre, Hun Sen dijo en una reunión a puerta cerrada del Consejo de Ministros que el juicio de Khem Sokha podría posponerse hasta 2024, después de las elecciones comunales y nacionales - un claro indicio de que este juicio se retrasó por motivos políticos (Sokhea 2020). Los analistas especulan que, si se lleva a cabo el juicio, sería posible que se le declarara culpable y después se le indultara. Hun Sen ha mostrado agilidad anteriormente para dividir y cooptar el liderazgo de la oposición. A inicios de octubre, los abogados de Kem Sokha solicitaron que se retomara el juicio. A pesar de la liberación bajo fianza de 70 activistas del PNRC, se ha seguido aprehendiendo y hostigando a otras figuras del partido.

La disolución del PNRC y el arresto de Khem Sokha no son asuntos meramente internos. En febrero, la Unión Europea anunció que suspendería parcialmente su acuerdo comercial preferente "Todo menos armas" con Camboya, medida que se implementó formalmente el 12 de agosto (European Commission 2020). Si bien se citó una amplia gama de abusos a los derechos humanos y cuestiones relacionadas con la independencia del poder judicial, quedó claro que la supresión de la oposición política y el encarcelamiento de su presidente fueron motivos cruciales de esta decisión. Esta posibilidad se había planteado en repetidas ocasiones desde la disolución del PNRC. La UE abrió formalmente el proceso en febrero de 2019 y envió reportes a Camboya en noviembre del mismo año. Si bien la liberación bajo fianza de Kem Sokha y de otros presos del PNRC en 2019 (en espera de juicio) probablemente fuera un gesto para apaciguar a la UE, el gobierno de Phnom Penh ha sido inflexible en sus declaraciones públicas de que no cumpliría con sus requisitos. China ha indicado que apoyaría a Camboya frente a las críticas de Occidente y el acuerdo comercial 
de julio entre ambos países, que se aborda más adelante, fue un claro símbolo de ello. Si bien aún no quedan claras las implicaciones finales de las restricciones de la UE, parecen acercar a Camboya al ámbito de influencia de China. Estados Unidos también ha criticado la desaparición del PNRC e impuesto restricciones al otorgamiento de visas a algunos funcionarios de gobierno como consecuencia, pero aún no ha hecho amenazas en relación con los acuerdos comerciales.

\section{CORONAVIRUS: SALUD Y ECONOMÍA}

Desde luego, 2020 fue el año en que el coronavirus cambió al mundo, y Camboya también sufrió profundos impactos en términos sociales y económicos, aunque debe enfatizarse que, al igual que ocurrió con sus vecinos, las cifras de casos reales en el país fueron notablemente bajas.

En las primeras etapas, cuando Wuhan, China, aún era claramente el epicentro de la pandemia, Hun Sen asumió una postura sólida de apoyo a China, insistió en que tenían todo bajo control, mantuvo abiertos los vuelos a China y se negó a llevar de vuelta a casa a los estudiantes camboyanos que se encontraban ahí. Declaró que deseaba visitar a los estudiantes camboyanos en Wuhan y, finalmente, después de una cumbre en Corea del Sur, viajó con su hijo Hun Manet a Beijing a principios de febrero. Con ello, fue el primer líder extranjero en visitar China desde que inició la crisis, pero no se le permitió continuar a Wuhan debido a los riesgos sanitarios. En su cuenta de Facebook, Hun Sen afirmó que sus motivos para ir a China eran mostrar su solidaridad con ese país, dar ánimos a los estudiantes camboyanos y a otros ciudadanos en China, y porque "envié mensajes a los ciudadanos camboyanos diciéndoles que su enfermedad no se debe al virus 'Corona', sino al miedo. Hasta ahora, ningún camboyano ha contraído la enfermedad. Algunos países parecen haber librado una guerra psicológica, infundiendo miedo a los ciudadanos” (The Star 2020).

Más adelante en este contexto, Hun Sen permitió que un crucero desembarcara en Sihanoukville en el mes de febrero. La infección se había difundido rápidamente en otros cruceros y, debido a que el Westerdam había atracado en Hong Kong, donde ya había reportes del virus, varios otros países le negaron la entrada a sus puertos, aunque se afirmaba que no 
transportaba ningún caso. El crucero, que llevaba más de 2200 pasajeros y tripulantes, había permanecido en un limbo durante varios días. Sin portar cubrebocas, Hun Sen saludó personalmente a los pasajeros estrechándoles la mano conforme bajaban del barco, y cada uno recibió flores y una mascada camboyana. Se habían realizado evaluaciones de salud a los pasajeros antes de bajar del crucero, pero el desastre pareció inminente cuando uno de ellos, que después viajó a Malasia, resultó positivo en la prueba que ahí le practicaron. Se suspendió el desembarco en Camboya, que seguía llevándose a cabo, y más adelante se determinó que el caso de Malasia era un falso positivo. El hecho de permitir el desembarco a los pasajeros fue una clara demostración de apoyo a China y un gesto magnánimo hacia un crucero al que otros países no habían permitido atracar, y recibió elogios del resto del mundo (Camboya sabía que, poco antes, la UE pretendía suspender su preferencia comercial por abusos a los derechos humanos). El crucero y muchos de sus pasajeros eran estadunidenses.

Vietnam cerró su frontera con Camboya el 19 de marzo, sin informarle a esta última de antemano (Bangkok Post 2020a), y Camboya hizo lo propio el día siguiente. A pesar de la preocupación inicial, pronto ambos países crearon un sistema para intercambiar productos alimentarios y otros bienes a través de su frontera cerrada, que se reabrió el 22 de junio con los mismos estrictos requisitos de monitoreo sanitario que se aplicaban a los visitantes de otros países. La situación fue más complicada en la frontera entre Camboya y Tailandia, debido a que numerosos camboyanos trabajan en Tailandia. Los reportes de que se cerraría la frontera con Tailandia, poco después del cierre de la frontera con Vietnam, provocaron que una oleada de trabajadores camboyanos volviera de Tailandia, aproximadamente 15000 durante un fin de semana (Tum 2020) (más trabajadores cruzarían de manera ilegal después del cierre de la frontera, y otros, enfrentando dificultades económicas, regresarían del mismo modo a Tailandia). Los agentes fronterizos se vieron abrumados por la carga de trabajo que implicó procesar todos los retornos, por lo que sólo se pidió a las personas que regresaron que se aislaran una vez que arribaran a sus aldeas natales. De nuevo, los observadores esperaban que esto causara un aumento masivo en los casos de covid-19, pero eso no sucedió. Tailandia, Vietnam y Laos también tuvieron tasas de contagio muy bajas. A inicios de octubre, Camboya sólo había reportado 280 casos y ninguna muerte. 
Para combatir la covid-19, Camboya recibió ayuda financiera y técnica de varios países (Alemania, Australia, Corea del Sur, Estados Unidos, Francia, Japón, Rusia, la Unión Europea, Vietnam, y China particularmente), así como de organizaciones internacionales (Heng y Len 2020), y también pudo haberse beneficiado del hecho de que una sólida institución de investigación epidemiológica, el Instituto Pasteur, haya estado en el país desde el periodo de la colonia francesa. Se implementaron fuertes medidas de distanciamiento social y se cerraron escuelas, templos y restaurantes. En abril se pospuso la celebración del Año Nuevo camboyano, se pidió a los empleados de gobierno que siguieran trabajando y se bloquearon las carreteras para evitar los viajes desde Phnom Penh a las provincias. Después se programó una festividad "compensatoria” en agosto. Para entonces, algunas medidas se estaban relajando y a fines de septiembre se abrieron las escuelas, cuando menos parcialmente.

Los vuelos que llegaban al país eran limitados, y después de varias semanas en las que los residentes de diversos países tuvieron totalmente prohibido entrar a Camboya, se implementaron rigurosos requisitos de ingreso de forma más general: en caso de ser necesario, un cuantioso depósito para cubrir los gastos hospitalarios en el país, un comprobante de contar con un seguro médico adecuado, la realización de pruebas en el país de origen y al arribo, y una cuarentena de dos semanas. Todo ello dificultó la entrada al país y disminuyó de manera importante el número de visitantes. Ya no se emitían visas de turista y el turismo internacional, que conforma un segmento importante de la economía, quedó prácticamente detenido. Xinhua reportó a mediados de julio que la llegada de turistas en los cinco primeros meses del año había descendido 59\% en comparación con el año anterior (Xinhua 2020).

Además del devastador efecto sobre el turismo, las fábricas redujeron su ritmo de producción, en un inicio debido a la falta de materias primas provenientes de China, aunque esto se resolvió en parte cuando el gobierno chino facilitó embarques especiales en marzo. Debido a que la pandemia afectó a la economía mundial, la industria experimentó una desaceleración más a largo plazo ante el descenso de la demanda internacional. El Ministerio del Trabajo dijo a inicios de septiembre que 81 fábricas habían cerrado y otras 491 habían suspendido operaciones temporalmente (Hun 2020). Los efectos sobre la economía se 
amplificaron por el regreso de los camboyanos que laboraban en el extranjero y la disminución de las remesas de dinero que mandaban. Un reporte publicado en julio demostró que hubo un descenso de $10 \%$ en el dinero que enviaban los trabajadores camboyanos desde Corea del Sur y Japón (Sorn 2020a). Todo ello se complicó aún más por las fuertes sequías. Por otro lado, el efecto del cambio en las políticas comerciales de la Unión Europea aún está por verse.

Camboya ha mantenido una tasa de crecimiento anual del PIB de alrededor de 7\% durante varios años. Los cálculos de la dimensión que tendrá el impacto de la pandemia han variado. En un inicio, en el mes de abril, el Banco Asiático de Desarrollo (BAsD) calculó que el crecimiento descendería a 2.3\% en 2020 (Asian Development Bank 2020). Si bien los pronósticos del efecto sobre la economía llegaron a ser de 5.5\% para el mes de septiembre, el BAsD calculaba una contracción de 4\% (Hun 2020). Es difícil saber cuáles serán las repercusiones a largo plazo. En julio, el gobierno comenzó a realizar transferencias de efectivo a los pobres, a una de cada seis familias aproximadamente, que sin duda habrán sido útiles. En julio, al mismo tiempo que emitió un préstamo de $\$ 250$ millones, el Banco Asiático de Desarrollo calculaba que Camboya perdería 390000 empleos (The Phnom Penh Post 2020) — cifras que probablemente no toman en cuenta el considerable efecto sobre la economía informal. Hay ciertos indicios de que el endeudamiento con las instituciones microfinancieras en zonas rurales (con el consecuente riesgo de pérdida de tierras), que ya era un problema crónico, se ha agravado por la economía pandémica (Blomberg y Mech, 2020). El número de personas que no logran pagar sus préstamos se duplicó en los primeros seis meses del año y mejoró ligeramente en julio. En abril, una encuesta entre hogares rurales encontró que uno de cada ocho había tenido que vender activos, como ganado, maquinaria o tierras, para pagar sus deudas.

En otro tema más positivo, Camboya intensificó sus alianzas comerciales con otros países, especialmente en Asia. En definitiva, el Tratado de Libre Comercio que se celebró con China en julio fue, en parte, una demostración simbólica de apoyo por parte de China frente a las restricciones comerciales de la Unión Europea y a la crisis de la pandemia (Sun 2020). El ministro de Relaciones Exteriores chino, Wang Yi, fue a Camboya el 12 de octubre para firmar el tratado formalmente, en la primera parada de una gira por cuatro países del 
sureste asiático (Aun 2020), que se describe en la prensa como una afirmación de las relaciones sinocamboyanas. En esa ocasión, Hun Sen se refirió específicamente al estatus del tratado "Todo menos armas” de la Unión Europea, que, afirmó, llegaría a su fin algún día, en tanto que el acuerdo con China duraría por siempre (Sao 2020).

Las exportaciones a China podrían centrarse primordialmente en productos agrícolas - quizá una vez que se cuente con la infraestructura correcta, lo que representa un cambio hacia este sector desde el turismo y la manufactura de prendas de vestir. Camboya tiene autorización para exportar mangos a China y busca obtenerla para productos como la pimienta, el nido de pájaro comestible, el durian, el coco, la pitahaya y el maíz rojo. Asimismo, a fines de septiembre se anunció que se habían firmado protocolos que le permitirían exportar carne de res a China por primera vez (Sorn 2020b). A pesar de la sequía, las exportaciones de arroz de Camboya aumentaron 10\% en comparación con el año anterior en los primeros nueve meses del año y el mayor importador fue China. Además, se estaba negociando un tratado comercial con Corea del Sur. Estados Unidos sigue siendo un cliente fuerte para las exportaciones de productos manufacturados en Camboya y se especula que, si Estados Unidos reduce su comercio con China, podría voltear a ver a países del sureste asiático, incluyendo Camboya, pero eso aún está por verse.

\section{DERECHOS HUMANOS}

Las organizaciones de derechos humanos criticaron severamente una ley de estado de emergencia por la covid-19 cuando los borradores se presentaron al público por primera vez a fines de marzo, y continuaron hasta que la iniciativa se aprobó para convertirse en ley el 27 de abril (Human Rights Watch 2020a). El texto de la iniciativa autorizaba extensas facultades de vigilancia pública y controles a las asambleas públicas, que, según los críticos, excedían las necesidades de la crisis sanitaria. De hecho, dado que Camboya logró mantener el número de casos de covid-19 en niveles muy bajos, la ley nunca se invocó. Sin embargo, podría decirse que algunas de las facultades que ésta otorgó se ejercieron en los arrestos políticos que se llevaron a cabo durante toda la pandemia sin tener que invocar la ley.

Camboya nunca ha tenido buenos antecedentes respecto a los derechos humanos, y es difícil saber qué tanto su historial en 2020 tuvo que ver con la pandemia, o bien fue una 
continuación de las políticas vigentes desde la supresión del PNRC en 2017. En los primeros meses de la pandemia, con fundamento en una ley de 2018, hubo aprehensiones debido a "noticias falsas" publicadas por periodistas y políticos de la oposición que criticaban el manejo de la crisis. La organización Human Rights Watch reportó que hubo 30 arrestos arbitrarios entre fines de enero y fines de abril (18 de ellos a miembros del PNRC), y sugirió que el gobierno empleaba las acusaciones de noticias falsas para ejercer represión política (Human Rights Watch 2020b). Un caso que tuvo mucha cobertura de prensa fue el de un periodista que citó directamente a Hun Sen de una manera que se percibió como crítica. VICE News reportó que en marzo se detuvo brevemente a una niña de 14 años que había escrito en Facebook que tres personas habían muerto y después se le obligó a disculparse ante su grupo escolar. Si bien esta historia sensacionalista probablemente es menos común que las aprehensiones de periodistas y figuras de la oposición, ilustra el grado al que las autoridades camboyanas estaban decididas a controlar la narrativa en torno a la enfermedad.

A inicios de julio, las autoridades evitaron que activistas y monjes se reunieran para conmemorar el cuarto aniversario del magnicidio del analista político Kem Lay. Además, se arrestó a una persona. Entre aquellos a quienes se desalojó estaban miembros de una organización de protesta juvenil recién formada, Khmer Thavarak, que comenzaba a hacerse sentir. El 22 de septiembre, la ONG de derechos humanos LICADHO publicó una lista de 19 arrestos que se habían llevado a cabo desde fines de julio (LICADHO 2020), comenzando con el de Rong Chhun. El líder sindical Rong Chhun, que había estado en prisión en dos ocasiones, era el más prominente entre los detenidos y su aprehensión dio lugar a otras protestas por parte de Khmer Thavarak y otras organizaciones, algunas de las cuales dieron lugar a otros arrestos. En esta ocasión, la detención de Rong Chhun no se debió a actividades relacionadas con los sindicatos, sino a que investigó quejas de invasión en la frontera con Vietnam, un tema al cual Hun Sen ha demostrado ser particularmente sensible en ocasiones anteriores. Entre las personas que aparecían en la lista de LICADHO había, como siempre, afiliados al PNRC. También había activistas por el medio ambiente afiliados al grupo Madre Naturaleza, un eterno dolor de cabeza para el gobierno, y dos jóvenes cantantes de rap cuyas letras se consideraban cuestionables. Las organizaciones de derechos humanos enfatizaron que los arrestos se debieron a la participación en protestas pacíficas y, con frecuencia, bastante inocuas. De nuevo, es difícil medir a qué grado las aprehensiones tienen que ver con 
la crisis sanitaria, pero puede ser que el gobierno fuera sensible a la respuesta del público a los controles por la pandemia y a la economía en contracción y estuviera decidido a no permitir que ninguna chispa de disenso se convirtiera en protestas más extensas. En octubre, al respecto de los arrestos recientes, Hun Sen dijo que "protegerían a las personas pobres de una población de 16 millones [...] Tenemos el deber de proteger la paz, la estabilidad política y el orden social. Si uno se levanta, se golpea a uno. Si dos se levantan, se golpea a dos" (Mech 2020).

Otro suceso que tuvo repercusiones internacionales fue el secuestro (y presunto homicidio) del activista tailandés exiliado Wanchalearm Satsaksit a plena luz del día en una calle de Phnom Penh a principios del mes de junio. Se presume que agentes tailandeses perpetraron el secuestro, que tuvo varios testigos y fue posterior a las desapariciones de activistas tailandeses residentes en Laos. El gobierno camboyano adujo ignorancia en un inicio y más adelante anunció que realizaría las investigaciones pertinentes (Reuters 2020a), aunque algunos siguen quejándose de que el gobierno ha ignorado los hechos. Asimismo, poco después del secuestro se llevaron a cabo manifestaciones frente a la embajada de Camboya en Tailandia. El suceso estuvo entre los temas que se reclamaron en las protestas masivas de jóvenes y estudiantes universitarios en Bangkok en septiembre.

\section{SIHANOUKVILLE}

Probablemente no haya nada más emblemático de la relación de China con Camboya que la presencia china en la ciudad portuaria de Sihanoukville, importante destino turístico. En mi artículo para el Anuario de 2018 describí algunas de las tensiones en torno a esta situación. La economía de la ciudad se había vuelto casi exclusivamente china y estaba basada en las apuestas en casinos. Una de las críticas era que se trataba de una economía burbuja, pues tanto inversionistas como clientes eran chinos y una proporción relativamente pequeña de los ingresos se inyectaban a la economía camboyana. Además, había quejas de que importantes delincuentes chinos habían entrado a la ciudad, lo que causó sentimientos en contra de ese país. Para complicar aún más las cosas, Estados Unidos alegó que había un acuerdo secreto desde hace tres años según el cual los chinos podían usar una base naval camboyana que se 
encuentra en el puerto - lo cual Phnom Penh negó- y hubo reportes de que se estaba construyendo una pista de aterrizaje de gran tamaño, supuestamente para aviones chinos.

El auge económico chino en Sihanoukville llegó a su fin repentinamente en 2019, cuando el gobierno chino, preocupado por la criminalidad y los efectos de las apuestas en la economía china, instó a Camboya a detener los juegos de azar por Internet. El país dejó de renovar las licencias en agosto y para fin de año se habían prohibido efectivamente todas las apuestas en línea, lo que tuvo repercusiones para los casinos en todo el país, pero más notoriamente para Sihanoukville (Turton 2020; Len 2020). Si bien los juegos de azar presenciales en casinos forman parte del panorama, se dice que las apuestas en línea generaban 90\% de las ganancias de los casinos en Sihanoukville, donde alrededor de 200000 personas laboraban en 200 establecimientos (se cree que la mayoría de las apuestas se hacían desde China a través de Internet, aunque los juegos de azar en línea son ilegales en ese país). Tanto a China como a Camboya les interesaba aminorar los sentimientos contra China. En todo el país, el número de casinos pasó de 163 a 118 entre junio de 2019 y fines de enero, mes en el cual 56 de ellos aún funcionaban en Sihanoukville. Se calcula que hasta 100000 personas dejaron la ciudad después de la prohibición, $\mathrm{y}$, según los informes del gobierno, para fines de enero, un total aproximado de 200000 chinos se habían marchado (Inside Asian Gaming 2020), todo ello en un periodo muy corto (algunos negocios de apuestas en línea pueden haberse reubicado en Filipinas). Se dice que han cerrado unos 800 restaurantes de Sihanoukville. Todo esto ocurrió antes de la pandemia, que evidentemente afectó aún más la economía basada en el turismo. Además de los chinos que trabajaban en Camboya, la prohibición afectó a muchos camboyanos que eran empleados de servicio, trabajadores de la construcción y emprendedores que tenían restaurantes y pequeños hoteles.

El auge y la caída de esta industria ilustraron algunas de las incertidumbres inherentes a los vínculos con una economía extranjera. Asimismo, mostró el grado al que las conexiones con "China" pueden representar muchas cosas, algunas contradictorias, y algunas no siempre bienvenidas por las autoridades chinas. Es probable que el boom de los casinos en línea haya terminado para siempre, aunque Sihanoukville aprovechará su economía nuclear como ciudad portuaria con varias zonas económicas especiales y un número menor de casinos para quienes deseen jugar en persona. Para junio de 2020 se reportaba que habían vuelto unos mil 
inversionistas chinos y que se habían reabierto los vuelos directos de China a Sihanoukville (Phoung 2020). Todos los casinos del país se habían cerrado en abril debido a la covid-19, pero se les permitió solicitar su reapertura con estrictas medidas sanitarias a partir de julio. El primero en abrir fue el gran Casino Naga en Phnom Penh. Para fines de septiembre, ocho casinos habían reabierto en Sihanoukville a pesar de la poca afluencia de turismo internacional.

Cuando se celebró el Tratado de Libre Comercio entre Camboya y China en octubre, también firmaron "intercambios de notas" para realizar estudios de viabilidad relativos a trabajos de mejora en el Hospital Provincial de Referencia de Sihanoukville y a un Proyecto de Desarrollo de Sistema de Drenaje Municipal, lo que pone de manifiesto que China reconoce una conexión especial con la economía de la ciudad (Sao 2020).

Mientras tanto, Estados Unidos ha seguido afirmando que existe un acuerdo secreto desde hace tres años para permitir el uso militar por parte de China de la Base Naval Camboyana Ream en Sihanoukville. Esto estuvo relacionado con otras afirmaciones contra Chinese Union Development Group, la empresa que desarrolla una gigantesca área de 45000 hectáreas en un parque nacional que se extiende desde la zona de Sihanoukville hasta el estado de Koh Kong. El área en desarrollo, que según se afirma es un complejo hotelero, incluye una enorme pista de aterrizaje y un puerto de gran calado que, se dice, parecía estar diseñado para operaciones militares. Camboya ha respondido que se planea que el aeródromo, que tendrá la pista más larga del país, sea un centro de transporte mundial (Beech 2019). El 9 de diciembre de 2019 el Departamento del Tesoro de Estados Unidos sometió a sanciones a un general camboyano, Kun Kim, junto con miembros de su familia y el magnate Try Pheap, debido a sus vínculos con el proyecto y a los reportes de abusos a los derechos humanos de los aldeanos de la zona, a quienes se obligó a dejar sus hogares. En septiembre de 2020, en virtud de la Ley Global Magnitsky sobre Responsabilidad de Derechos Humanos, el alcance de las sanciones se amplió para incluir a todo Union Development Group, con base en afirmaciones de que dicha empresa había falsificado documentos de registro y desplazado poblaciones locales (Camboya respondió que, puesto que era un parque nacional, el asentamiento de los aldeanos era ilegal). La embajada china en Phnom Penh y el Consejo de Desarrollo de Camboya condenaron las sanciones de inmediato. Según se dijo, Hun Sen 
aseguró posteriormente al embajador de Estados Unidos, en una reunión que sostuvieron más adelante ese mes, que China no tendría acceso a la Base Naval Ream. Las imágenes de satélite mostraron la destrucción a principios de septiembre de un edificio que Estados Unidos había regalado hacía ocho años, lo que para algunos fue una prueba más de la postura contra Estados Unidos y la futura presencia china en la base (Asia Maritime Transparency Initiative, 2020). Camboya afirmó que el remozamiento se había planeado desde hacía mucho tiempo y que la ayuda de los chinos para los proyectos de construcción en la base no implicaba su presencia militar.

\section{¿Desastre ECOLÓGICO?}

Quizá el suceso más trascendente del año fue el drástico descenso del caudal del río Mekong. Uno de los accidentes geográficos más importante de Camboya es el enorme lago Tonle Sap, que se encuentra en el noroeste y se conecta con el río Mekong a través del río Tonle Sap. Cualquier información introductoria sobre Camboya indica que, una vez al año, las aguas del Mekong son tan abundantes que desbordan sus márgenes y el flujo es lo suficientemente fuerte para causar que el río Tonle Sap cambie de dirección y fluya corriente arriba hacia el lago. El lago Tonle Sap tiene sus propios patrones de inundación, intrínsecos al ciclo de cultivo de arroz de la zona, que básicamente es el corazón agrícola del país. El momento en que el río revierte su flujo también es notable, porque se puede capturar fácilmente a los peces pequeños en el sitio donde se invierte el cauce. En 1999 la reversión se dio más tarde que nunca antes y en 2020 simplemente no sucedió.

Si bien ha habido cierta cobertura de prensa al respecto, no se ha hecho suficiente énfasis en lo graves que serán las consecuencias. Este suceso afecta a un sistema ecológico que ha sido la base del sistema agrícola natural de Camboya desde el neolítico — parte de la base, por ejemplo, del sistema agrícola del país que existía en la época de Angkor.

Sobra decir que las implicaciones hidrológicas son complejas y estamos muy lejos de comprenderlas totalmente. La sabiduría popular de Camboya sostiene que esto se debe a las presas que hay aguas arriba, en China. Esta teoría parece encontrar apoyo, por ejemplo, en un artículo publicado en el The New York Times que, con base en datos satelitales recabados 
por el grupo Eyes on Earth [Ojos sobre la Tierra] en 2019, afirmaba que en las zonas aledañas a los tramos superiores del río, en China, no se presentó la misma sequía que en otros países del sureste asiático (Beech 2020). Algunas fuentes estadunidenses sugieren que el río Mekong representa una dinámica geopolítica en la que el dominio creciente de China puede compararse con su papel en el Mar de la China Meridional (Johnson y Wongcha-um 2020). Las fuentes chinas sugieren que existe un esfuerzo común de propaganda estadunidense para dar una imagen negativa de China y "sembrar discordia." Los hidrólogos sostienen que una presa hidroeléctrica por sí misma no causa inundaciones ni sequías significativas. El argumento contra China es que está reteniendo el agua en diversos embalses. Sin embargo, los chinos apuntan a fallas en la investigación y afirman que esos embalses que se localizan río arriba no tienen la capacidad suficiente para afectar el flujo del agua al grado que se afirma (Yuwei y Xiaoyi 2020). En todo caso, no todas las presas se encuentran en China, también las hay en Laos y en la misma Camboya (muchas de ellas son proyectos de inversión china, aunque la empresa estadunidense General Electric también ha participado en el equipamiento de las que se encuentran en Laos). Sin duda, el cambio climático también es un factor de esta ecuación.

No obstante, por el momento es difícil concebir una explicación para el descenso en el flujo del agua que no tenga que ver, al menos parcialmente, con la explotación río arriba por parte de China. Este país no forma parte del organismo coordinador que ha existido durante mucho tiempo, la Comisión del Mekong, pero en los últimos años formó su propio grupo, Cooperación Lancang Mekong — que, según afirma Estados Unidos, es un medio para relegar a la primera institución, asunto que se ha convertido en otra fuente de tensión. En temas más positivos, en agosto las autoridades tailandesas anunciaron que China estaba dispuesta a compartir sus datos relativos al agua (Bangkok Post 2020b).

Aún está por verse si la disminución del caudal continúa en los próximos años, si las nuevas estrategias de irrigación o un cambio en el enfoque económico pueden ser suficientes para abordar los problemas y si una mayor cooperación con China puede resolver algunos de ellos. Hasta ahora, ninguno de los países que están aguas abajo se ha quejado formalmente con China, aunque cada vez es más común entre la población en general adjudicarle la culpa. 
La situación subraya el grado al que Camboya, un aliado que ha sido muy leal a China en los últimos años, en muchos sentidos también es vulnerable a las políticas de esta última.

Mientras tanto, la posibilidad de un segundo año de sequía es muy real, lo que afectará la disponibilidad de pescado y del agua indispensable para el cultivo de arroz por irrigación. En agosto, el Comité Nacional para la gestión de desastres reportó que unas 40000 hectáreas de cosecha de arroz habían quedado destruidas debido a la sequía, que afectó en particular a las provincias del noroeste del país (Khouth 2020a). Hun Sen afirmó en un discurso pronunciado en octubre que, a pesar de las lluvias recientes, el nivel del río estaba entre cuatro y cinco metros más abajo de lo normal (Khouth 2020b). (Aunque más adelante las lluvias torrenciales causaron inundaciones en varias zonas, la situación no parece haber mejorado significativamente.) Hun Sen afirmó: "Insto a la gente a trabajar en conjunto para pensar en formas de conservar el agua [...] Debemos hacer acopio de salsa de soya, fideos, arroz y todo tipo de vegetales y medicamentos para salvar a nuestro pueblo de la hambruna". Había planes para aumentar el financiamiento público de los nuevos esquemas de irrigación.

\section{TRIBUNAL DEL KHMER ROJO}

Si bien el Tribunal del Khmer Rojo (tribunal para el genocidio camboyano) siguió laborando a lo largo de 2020, y aunque los fiscales internacionales han instado al enjuiciamiento de otras tres figuras, sus contrapartes camboyanas los han bloqueado. Hun Sen ha dejado claro durante mucho tiempo que quería que los juicios se limitaran a unas cuantas figuras importantes. A inicios de 2020 era evidente que el tribunal no tenía un futuro efectivo. Los observadores internacionales del juicio se retiraron en septiembre. De los cinco líderes del Khmer Rojo que el Tribunal ha procesado desde su creación en 2006, uno murió antes de las audiencias y a otro se le declaró incapaz para presentarse a juicio (y también murió posteriormente). Se enjuició a las tres figuras restantes y se les declaró culpables durante la larga trayectoria del tribunal. Nuon Chea, de quien a veces se dice que era el segundo al mando del Khmer Rojo después de Pol Pot, y a quien se declaró culpable de crímenes de lesa humanidad (en 2014) y de genocidio (en 2018), murió en agosto de 2019 a la edad de 93 años. Kaing Guek Eav, a quien se conocía como Duch y quien fuera director de una infame prisión del Khmer Rojo, murió el $1^{\circ}$ de septiembre de 2020 con 77 años. En 2010 se le declaró 
culpable de crímenes de lesa humanidad, crímenes de guerra, homicidio y tortura. El único que se sometió a juicio, Khieu Samphan, jefe de Estado durante el periodo de Pol Pot, fue sentenciado junto con Nuon Chea en 2014 y 2018. Tras su fallo de culpabilidad en 2018, sometió una solicitud para descalificar a los seis jueces de su apelación, la cual se rechazó en julio de 2020, lo que fue un tanto predecible. De hecho, ésta fue la última decisión judicial importante del Tribunal.

Traducción: María Capetillo Lozano

John A. Marston es profesor en el Centro de Estudios de Asia y África de El Colegio de México. Su interés en Camboya surgió a partir de su trabajo en la década de 1980 en un campo de refugiados en la frontera entre Tailandia y Camboya y en el Centro de Procesamiento de Refugiados Filipinos. Completó un doctorado en Antropología en la Universidad de Washington, en 1997, y se basó en su investigación de campo en Camboya en 1992-1994. Es coeditor del libro El budismo en Camboya: Historia y etnografía (El Colegio de México 2006) y coordinador de las obras Antropología y comunidad en Camboya y Tailandia (El Colegio de México 2011) y La antropología de las fronteras de Tailandia como espacios de flujo (El Colegio de México 2016). Sus artículos han aparecido en varias revistas académicas como Estudios de Asia y África, Journal of Southeast Asian Studies, Contemporary Buddhism y en Southeast Asian Affairs, y como capítulos en muchos otros volúmenes. Con regularidad lleva a cabo sus investigaciones en Camboya.

\section{jmars@colmex.mx}

\section{REFERENCIAS}

Asia Maritime Transparency Initiative. 2020. “Changes Underway at Cambodia's Ream Naval Base.” Asia Maritime Transparency Initiative, octubre 2, 2020. https://amti. csis.org/changes-underway-at-cambodias-ream-naval-base/

Asian Development Bank. 2020. "Cambodia's Economic Growth to Slow in 2020, Rebound Expected in 2021 - ADB.” Boletín informativo, abril 3, 2020. https://www.adb. org/news/cambodias-economic-growth-slow-2020-rebound-expected-2021-adb 
Aun Chhengpor. 2020. "In Cambodia, China's Wang Yi Set to Challenge US Pressures." South China Morning Post, octubre 11, 2020. https:/www.scmp.com/week-asia/ politics/article/3104988/cambodia-chinas-wang-yi-set-challenge-us-pressures

Bangkok Post. 2020a. "Vietnam shutters borders with Cambodia as pandemic spreads." Bangkok Post, marzo 19, 2020. https:/www.bangkokpost.com/world/1882310/viet nam-shutters-borders-with-cambodia-as-pandemic-spreads

Bangkok Post. 2020b. "China 'ready to share Mekong data': Concern grows about low water levels and dam development." Bangkok Post, agosto 21, 2020. https:// www.bangkokpost.com/thailand/general/1972411/china-ready-to-share-mekongdata

BBC. 2020. “Coronavirus: How did Cambodia's cruise ship welcome go wrong?” $B B C$, febrero 20, 2020. https://www.bbc.com/news/world-asia-51542241

Beech, Hannah. 2019. "A Jungle Airstrip Stirs Suspicions About China's Plans for Cambodia." The New York Times, diciembre 22, 2019. https://www.nytimes.com/ 2019/12/22/world/asia/cambodia-china-military-bases.html

Beech, Hannah. 2020. "China Limited the Mekong's Flow. Other Countries Suffered a Drought." The New York Times, abril 13, 2020. https://www.nytimes.com/2020/ 04/13/world/asia/china-mekong-drought.html

Blomberg, Matt y Mech Dara. 2020. "Land to lose: coronavirus compounds debt crisis in Cambodia." Thomas Reuters Foundation, septiembre 21, 2020. https://www.reuters. com/article/us-cambodia-finance-loans-idUSKCN26C02S

Chhem Rethy y Chhem Sirika. 2020. “Cambodia global health diplomacy: The 'Westerdam' cruise ship saga." Khmer Times, marzo 26, 2020. https://www.khmertimeskh.com/ 705764/cambodia-global-health-diplomacy-the-westerdam-cruise-ship-saga/

European Commission. 2020. "Cambodia Loses Duty-free Access to the EU Market Over Human Rights Concerns.” Boletín de prensa, European Commission, agosto 12, 2020. https://trade.ec.europa.eu/access-to-markets/en/news/cambodia-loses-dutyfree-access-eu-market-over-human-rights-concerns 
Heng, Kimkong y Len Ang. 2020. “Who’s Helping Cambodia Weather Covid-19?” The Diplomat, julio 21, 2020. https://thediplomat.com/2020/07/whos-helping-cambodiaweather-covid-19/

Human Rights Watch. 2020a. "Cambodia: Emergency Bill Recipe for Dictatorship. Covid19 Crisis Pretext for Hun Sen to Seek Unlimited Powers, Go After Critics." Human Rights Watch, abril 2, 2020. https://www.hrw.org/news/2020/04/02/cambodiaemergency-bill-recipe-dictatorship

Human Rights Watch. 2020b. "Cambodia: Covid-19 Spurs Bogus 'Fake News' Arrests. Renewed Crackdown on Opposition Supporters, Critics.” Human Rights Watch, abril 29, 2020. https://www.hrw.org/news/2020/04/29/cambodia-covid-19-spurs-bogusfake-news-arrests

Hun Sirivadh. 2020. "Garments Slump Spills Over to Surrounding Businesses, Residents.” Voice of Democracy, septiembre 26, 2020. https://vodenglish.news/garments-slumpspills-over-to-surrounding-businesses-residents/

Hunt, Luke. 2020. "US Imposes Sanctions on Chinese Company for Rights Abuses in Cambodia." The Diplomat, septiembre 15, 2020. https://thediplomat.com/2020/ 09/us-imposes-sanctions-on-chinese-company-for-rights-abuses-in-cambodia/

Inside Asia Gaming. 2020. “Government says 200,000 Chinese nationals have left Cambodia following online gambling ban." Inside Asia Gaming, agosto 31, 2020. https://www.asgam.com/index.php/2020/01/31/government-says-200000-chinesenationals-have-left-cambodia-following-online-gambling-ban/

Johnson, Kay y Panu Wongcha-um. 2020. "Water Wars: Mekong River Another Front in U.S.-China Rivalry.” Reuters, julio 24, 2020. https://www.reuters.com/article/usmekong-river-diplomacy-insight-idUSKCN24P0K7

Khouth Sophak Chakrya. 2020a. "Severe drought takes toll on 40,000ha rice crops across country." Phnom Penh Post, agosto 6, 2020. https:/www.phnompenhpost.com/ national/severe-drought-takes-toll-40000ha-rice-crops-across-country 
Khouth Sophak Chakrya. 2020b. "Drought fears persist despite rainstorms." Phnom Penh Post, octubre 8, 2020. https://www.phnompenhpost.com/national/drought-fearspersist-despite-rainstorms

Kijewski, Leonie. 2019a. “Cambodian Opposition Leader Doesn't Return as Promised.” Voice of America, noviembre 9, 2019. https://www.voanews.com/east-asiapacific/cambodian-opposition-leader-doesnt-return-promised

Kijewski, Leonie. 2019b. "Cambodian Opposition Leader Kem Sokha Freed from House Arrest." Al Jazeera, noviembre 10, 2019. https://www.aljazeera.com/news/2019/11/ 10/cambodian-opposition-leader-kem-sokha-freed-from-house-arrest

Len Ang. 2020. "Online Gambling: The Trap of Cambodian Dependency on Chinese Investment in Sihanoukville." Cambodianess, septiembre 21, 2020. https://cambodianess.com/article/online-gambling-the-trap-of-cambodiandependency-on-chinese-investment-in-sihanoukville

LICADHO. 2020. “Timeline: Recently Imprisoned Human Rights Defenders in Cambodia." LICADHO, septiembre 22, 2020. https://www.licadho-cambodia.org/articles/ 20200922/169/index.html

Mech Dara. 2020. "Ex-CNRP Commune Councilor Arrested Over Years-Old Forestry Charge." Voice of Democracy, octubre 7, 2020. https://vodenglish.news/ex-cnrpcommune-councilor-arrested-over-years-old-forestry-charge/

Phoung Vantha. 2020. "Chinese Investors Cautiously Return to Sihanoukville." Cambodianess, junio 16, 2020. https://cambodianess.com/article/chinese-investorscautiously-return-to-sihanoukville

Reuters. 2020a. "Cambodia to Investigate Kidnapping of Exiled Thai Activist." Reuters, junio 9, 2020. https://www.reuters.com/article/us-cambodia-thailand-disappearanceidUSKBN23G1DK

Reuters. 2020b. "China Ready to Share Water Data with Mekong Nations, Thailand Says." Reuters, agosto 19, 2020. https://www.reuters.com/article/us-mekong-river/chinaready-to-share-water-data-with-mekong-nations-thailand-says-idINKBN25H1JC 
Rostowska, Maya y Hind Hassan. 2020. "Cambodia Made a 14-Year-Old Apologize to Her Class for Texting About Coronavirus.” VICE News, junio 25, 2020. https://www.vice. com/en/article/ep4pdn/cambodia-made-a-14-year-old-apologize-to-her-class-fortexting-about-coronavirus

Sao Phal Niseiy. 2020. "Cambodia Forges Closer Ties with China by Signing Bilateral Trade Deal." Cambodianess, octubre 12, 2020. https://cambodianess.com/article/cambodiaforges-closer-ties-with-china-by-signing-bilateral-trade-deal

Sokhean, Ben. 2020. "Sokha Case May be Delayed for Up to Four Years." Khmer Times, septiembre 7, 2020. https://www.khmertimeskh.com/50761168/sokha-case-may-bedelayed-for-up-to-four-years/

Sorn Sarath. 2020a. "Money Sent Back from South Korea, Japan Declines.” Khmer Times, julio 14, 2020. https://www.khmertimeskh.com/744529/money-sent-back-fromsouth-korea-japan-declines/

Sorn Sarath. 2020b. "Beef to Be Sent to China for the First Time." Khmer Times, septiembre 30, 2020. https://www.khmertimeskh.com/50768093/beef-to-be-sent-to-china-forfirst-time/

Sun Narin. 2020. "China, Cambodia Conclude 'Mutually Beneficial' Free Trade Agreement." Voice of America, julio 21, 2020. https://www.voacambodia.com/a/ china-cambodia-conclude-mutually-beneficial-free-trade-agreement/5511289.html

The Phnom Penh Post. 2020. “ADB Says Cambodia to Lose 390,000 Jobs Due to Covid-19.” The Phnom Penh Post, julio 16, 2020.

The Star. 2020. "Cambodian PM explains His Decision to Visit China." The Star, febrero 7, 2020. $\quad$ https://www.thestar.com.my/news/regional/2020/02/07/cambodian-pmexplains-his-decision-to-visit-china

Tum, Malis. 2020. “Cambodian Migrant Workers Rush Back as Thai Border Closed.” Voice of America, marzo 22, 2020. https:/www.voacambodia.com/a/cambodian-migrantworkers-rush-back-as-thai-border-closed-/5342686.html 
Turton, Shaun. 2020. "Cambodia's Boomtown, a Gamble on Chinese Money Goes Sour." Nikkei Asia Review, enero 10, 2020. https://asia.nikkei.com/Business/Industry-infocus/In-Cambodia-s-boomtown-a-gamble-on-Chinese-money-goes-sour

Xinhua. 2020. "Intl Tourist Arrivals to Cambodia Down 59 pct in First 5 Months Due to Covid-19." XinhuaNet, julio 15, 2020. http://www.xinhuanet.com/english/2020-07/ 15/c_139213922.htm

Yuwei, Hu y Lin Xiaoyi. 2020. 'US-backed Institutions' Hyping China's 'Dams Threat' in Mekong River Riddled with Loopholes: Expert.” Global Times, septiembre 11, 2020. https://www.globaltimes.cn/content/1200571.shtml 